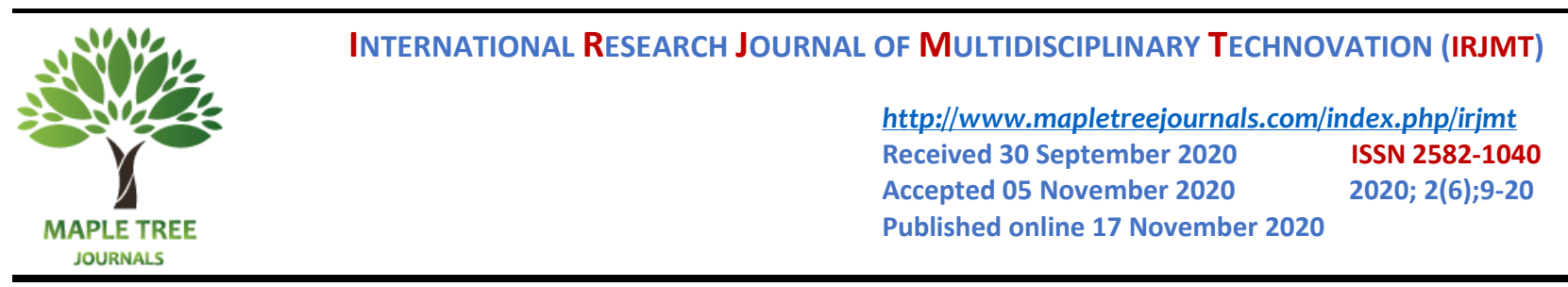

\title{
Investigations on Phase Change Materials for Thermal Energy Storage (TES) System for Low-Temperature Steam Applications
}

\author{
Paul Gregory F ${ }^{1,}$, R. Velavan ${ }^{1}$, K. Kannan ${ }^{1}$ \\ ${ }^{1}$ Department of Mechanical Engineering, PSG College of Technology, Coimbatore, 641004, India. \\ *Corresponding author E-Mail ID: meetwritergregory@aol.com \\ DOI: https://doi.org/10.34256/irjmt2062
}

\begin{abstract}
Phase Change Materials (PCM) exhibit a thermal storage property by their latent heat of fusion. These PCMs absorb heat energy from the source and they undergo a change of phase and release the stored heat energy to the application when required. This research work focuses on utilizing this property of PCMs to store heat energy from a steam source from a Parabolic Trough Collector, and the output from such a Thermal Energy Storage Unit could be used for steam cooking. This research work selects the optimum Phase Change Material to suit the heating application and virtually simulates the performance of various configurations of Thermal Storage heat exchangers and finds the optimum number of passes for steam flow using the Computational Fluid Dynamics (CFD) approach.
\end{abstract}

Keywords: Latent Heat of Fusion, Parabolic Trough Collector, Computational Fluid Dynamics.

\section{Introduction to Phase Change Materials}

With the depleting sources of energy, the day requires to optimally solar store the available energy and device technologies for the same. In another context, it would be also necessary to conserve excess energy to store them and to use the same when necessary. In an attempt to devise a system to store thermal energy, it is found that Phase Change Materials are an excellent source of storing thermal energy owing to their high heat of fusion [1]. Thermal Energy Storage can be done either as Sensible Heat Energy Storage or as latent energy storage [2]. Sensible Heat Energy is storage heat energy by creating a temperature difference. Phase Change Material falls under the category of Latent Heat Energy Storage. These phase change materials initially remain in their original phase. Whenever heat energy is applied to them, the molecules of the phase change materials move apart and hence there occurs a change of phase. There is no change in temperature and the heat energy is stored wholly by the Latent Heat property of the PCM. Whenever a lower energy entity is brought in contact with the PCM, this stored energy is transferred to the entity, thereby the PCM changing its phase. The PCM releases the stored energy to the entity and comes back to the original phase. This cycle repeats itself confined to the critical points of the Phase Change Material. While Organic Phase Change Materials suffer from major disadvantages like low thermal conductivity and flammability, Inorganic Phase Change Materials have high melting enthalpy and high density [4]. Hence inorganic phase change materials perform better than organic phase change materials for low-temperature applications.

\section{Physical Configuration of the Thermal Energy Storage system}

In this research work, steam from an array of Parabolic Trough Collectors has been used for steam cooking. An intermediate thermal storage system will tap the excess energy to charge 
the phase change material and such heat energy stored can be used to generate steam even when the solar energy source is not available. This process can be performed daily by charging and discharging the PCM, thereby utilizing the steam for cooking purposes. The Physical Configuration of the system is as shown in Figure 1.

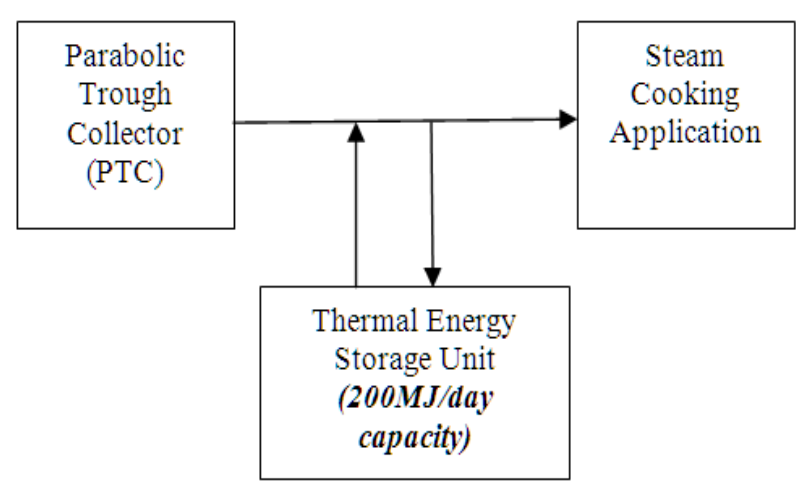

\section{Figure 1. Physical Configuration of the TES system}

\section{Selection of Phase Change Material for TES system}

The major requirements that should be considered in selecting a PCM for the TES system are as follows:

1. The PCM must have high energy density.

2. There must not be any significant change in volume inside the storage unit during Phase Change.

3. It must not be flammable and must be intoxic.

4. It must have a high Latent Heat of Fusion.

5. The melting point of the Phase Change Material should be in the desired temperature range [4]

6. Long term chemical stability [4]

7. PCM must be economically feasible.

The steam from the PTC will be about $150^{\circ} \mathrm{C}$ and hence the melting point of the Phase Change Material must be around $130^{\circ} \mathrm{C}$. Hence by taking into consideration the requirements, the following PCMs were shortlisted as listed in Table 1.

Table 1. Shortlisted Phase Change Materials

\begin{tabular}{|l|l|l|}
\hline Phase Change Material & Melting Point $\left({ }^{\mathbf{0}} \mathbf{C}\right)$ & Latent Heat of Fusion ( k J/kg) \\
\hline $\mathrm{LiNO}_{3}-\mathrm{KNO}_{3}[6]$ & 133 & 150 \\
\hline Erythritol & 132 & 339.8 \\
\hline $\mathrm{KNO}_{3}-\mathrm{NaNO}_{2}[6]$ & 141 & 97 \\
\hline Cross-linked HDPE [7] & $126-146$ & $167-201$ \\
\hline $\mathrm{NaC}_{2} \mathrm{H}_{3} \mathrm{O}_{2} \cdot 3 \mathrm{H}_{2} \mathrm{O}[7]$ & 137 & 172 \\
\hline
\end{tabular}


Erythritol has been chosen as the Phase Change Material for this application. VIKOR Algorithm [8] has been adopted as the appropriate method to prioritize and evaluate Phase Change Materials. Yi Wang et al [8] has compared many algorithms (TOPSIS, ANP, DEMATEL, VIKOR) and has concluded that VIKOR would best suit PCM Selection. The scheme of operation of the VIKOR Algorithm is as shown in Figure 2.

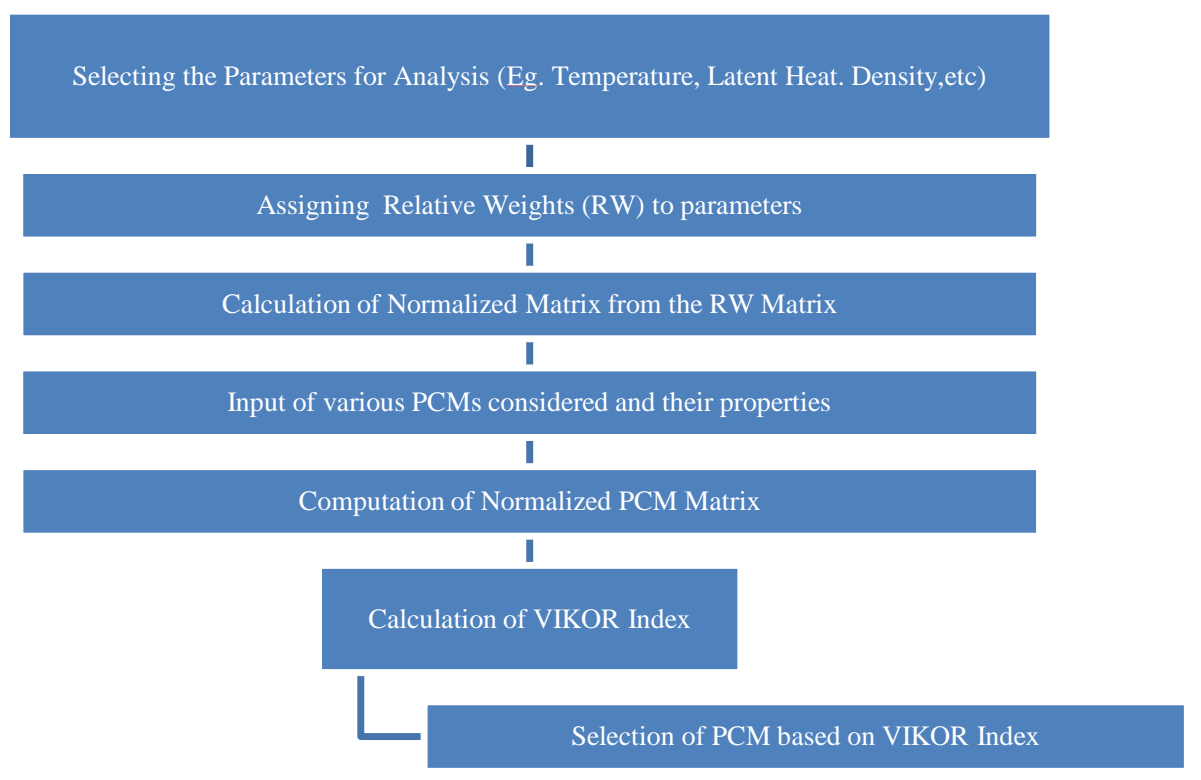

\section{Figure 2. Schematic of VIKOR Algorithm for selection of PCM}

The requirement of heat for steam cooking application has been estimated to be $200 \mathrm{MJ} /$ day and hence the TES unit must have a capacity of storing $200 \mathrm{MJ}$ of heat/day. The latent heat of fusion of erythritol being $339.5 \mathrm{~kJ} / \mathrm{kg}$. Hence the quantity of erythritol required to store $200 \mathrm{MJ}$ of heat is $590 \mathrm{~kg}$.

\section{Design of various configurations}

Various configurations of the TES system were designed and a CFD Analysis was done. Various configurations that were taken up for analysis are shown in Fig.3(a)- 3(i)

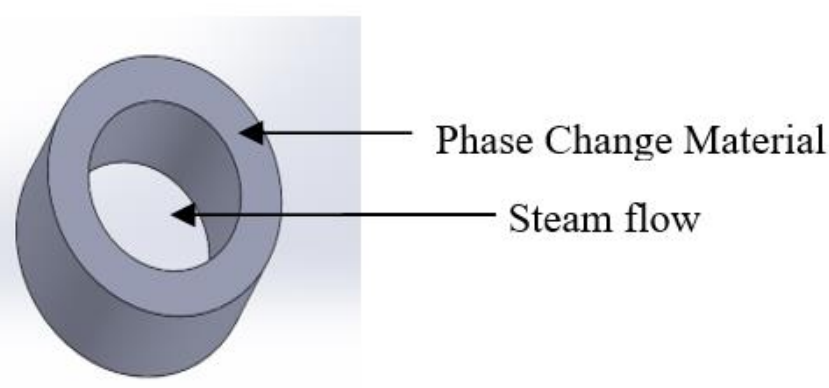

Fig.3 (a) Single Pass Configuration 

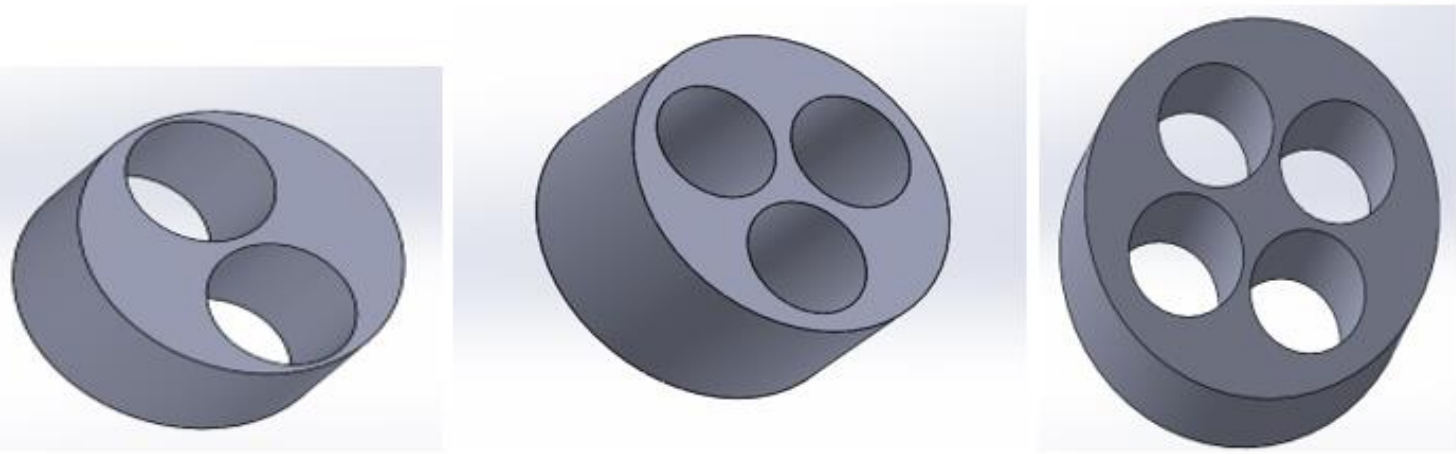

Fig. 3(b)Two Pass

Fig. 3(c)Three Pass

Fig. 3(d)Four Pass

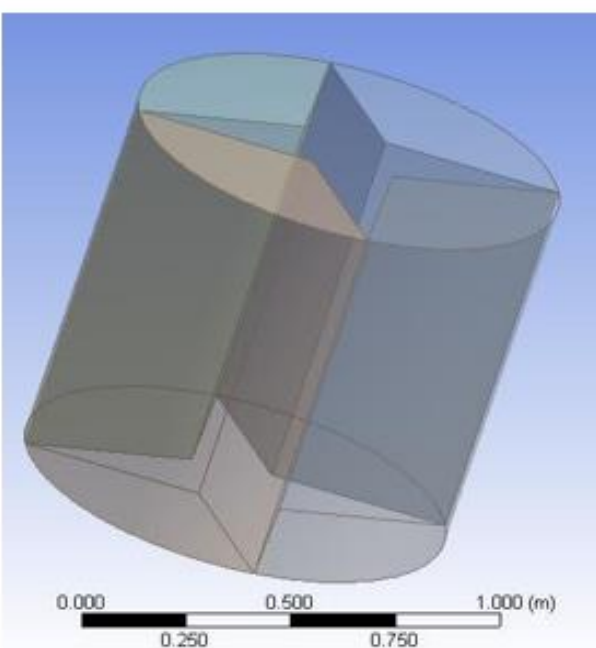

Fig. 3(e)Star Pass
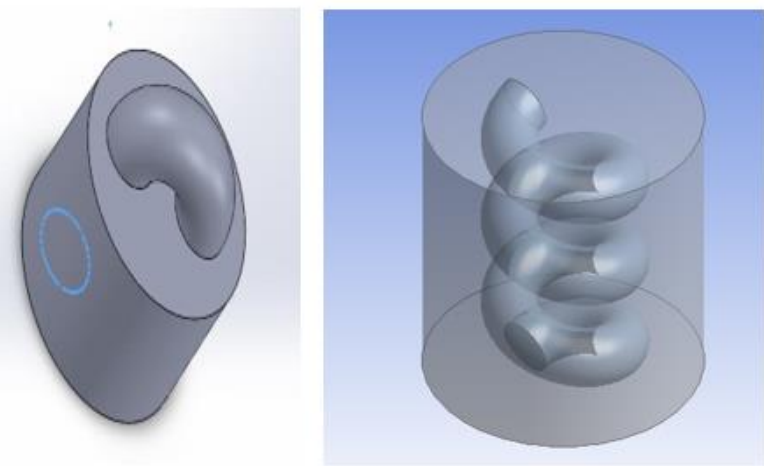

Fig. 3(g) Bent Tube

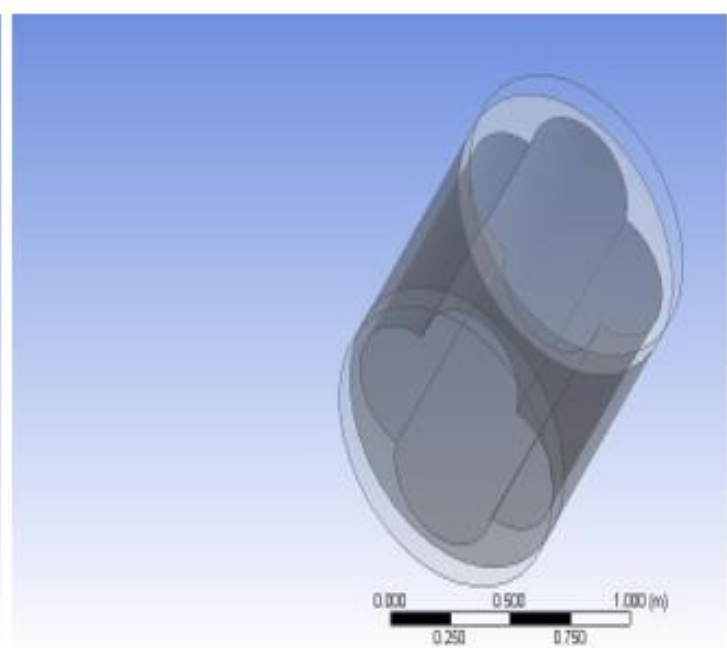

Fig. 3(f)Lobe Pass

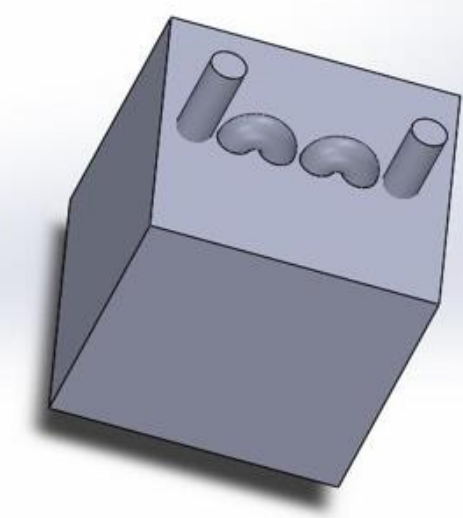

Fig. 3(i) Multi bent 
CFD Analysis was done for various configurations and the charging time for each configuration was estimated. The temperature contours at a fully charged condition are as shown in Fig.4(a) - 4(i) for various configurations.

\section{Temperature contour of various configuration at fully charged state}

A Computational Fluid Dynamics (CFD) analysis has been performed using ANSYS FLUENT 15.0 facility. The boundary conditions that were applied for the simulations are shown in Table.2. FLUENT was chosen for analysis as it is having excellent turbulence modeling phenomena and also is best suitable whenever transition analysis has to be modeled. Since PCMs also involve transition conditions, FLUENT was chosen to be suitable. The temperature contour at fully charged conditions is shown in Fig.4(a) - 4(i)

\section{Table 2. Boundary conditions for CFD Analysis}

\begin{tabular}{|c|c|}
\hline Heat Transfer Boundary Condition & $\begin{array}{l}\text { - Inlet Steam Temperature specified (423 K). } \\
\text { - Heat Transfer Coefficient Specified. } \\
\text { - Interface Coupling assured. }\end{array}$ \\
\hline $\begin{array}{l}\text { Phase Change Material Boundary } \\
\text { Conditions }\end{array}$ & $\begin{array}{l}\text { - Solidification and Melting Module Used. } \\
\text { - } \quad \text { Phase Change Temperature Specified. } \\
\text { - Material Properties provided. }\end{array}$ \\
\hline Steam Flow Boundary Conditions & $\begin{array}{l}\text { - } \mathrm{K} \text { - Epsilon model was used. } \\
\text { - } \mathrm{Re}-\text { Normalization Group (RNG) Adopted }\end{array}$ \\
\hline Transient Boundary Conditions & $\begin{array}{l}\text { - } \quad \text { Adaptive Time Stepping Method Applied } \\
\text { - } \quad \text { Standard Initialization (Single Inlet) }\end{array}$ \\
\hline
\end{tabular}

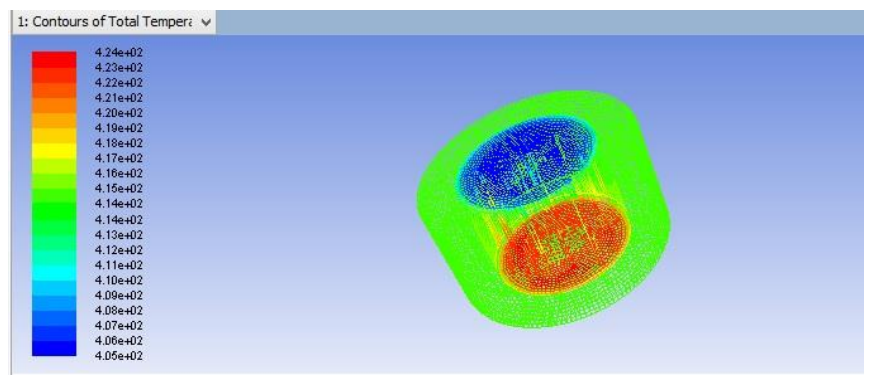

Fig. 4(a) Single Pass 
Paul Gregory F et al. / International Research Journal of Multidisciplinary Technovation 2020; 2(6): 9-20

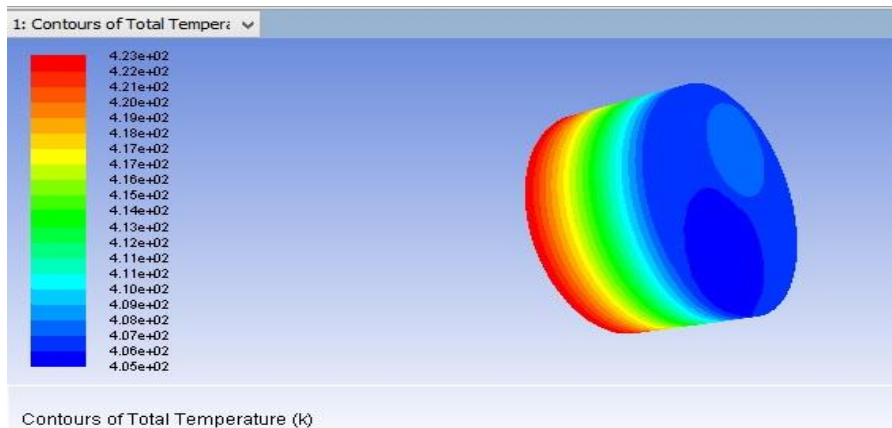

Fig. 4(b) Two-Pass

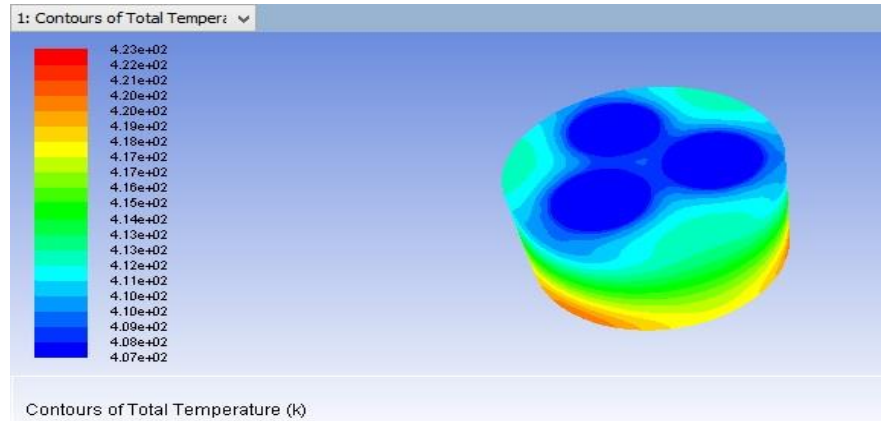

Fig. 4(c) Three Pass

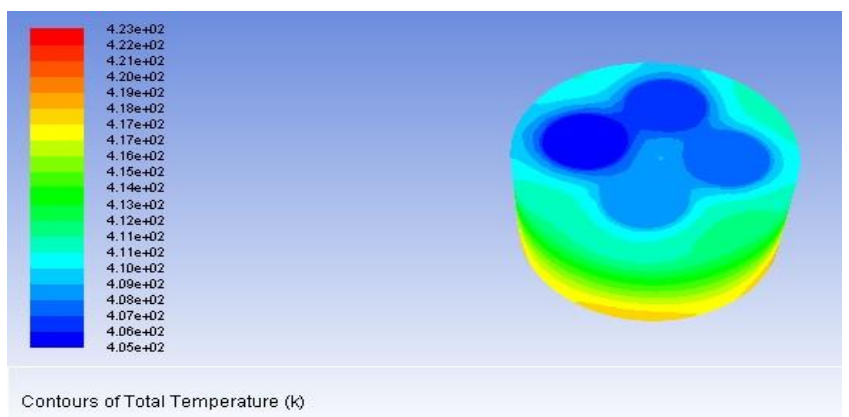

Fig. 4(d) Four Pass

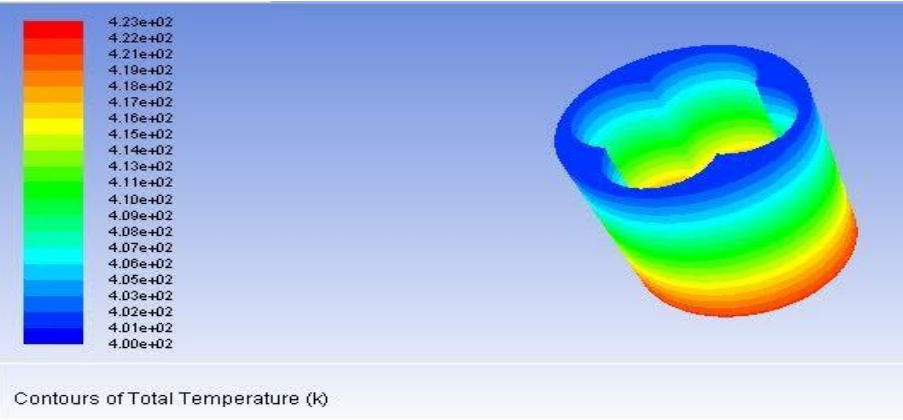

Fig. 4(e) Lobe Pass 


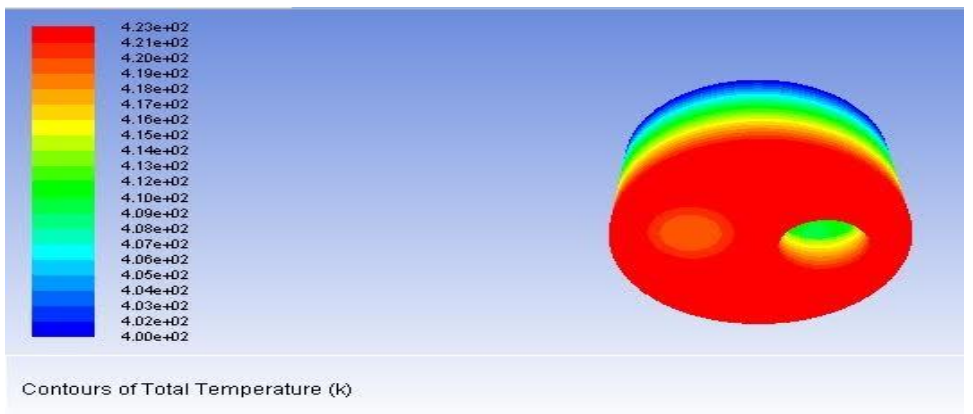

Fig. 4(f) Bent Pass

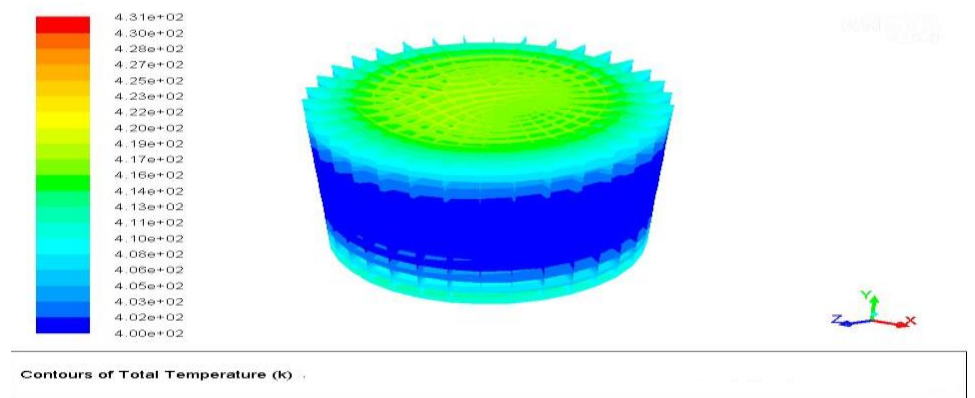

Fig. 4(g) Helical Pass

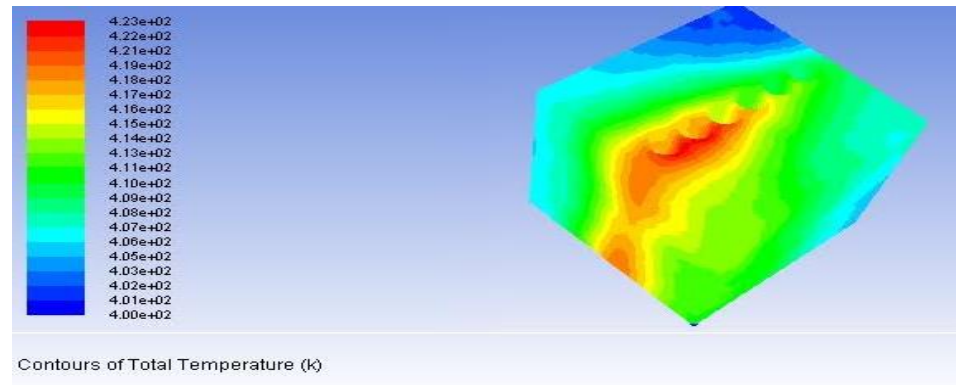

Fig. 4(h ) Multiple Bent Pass 


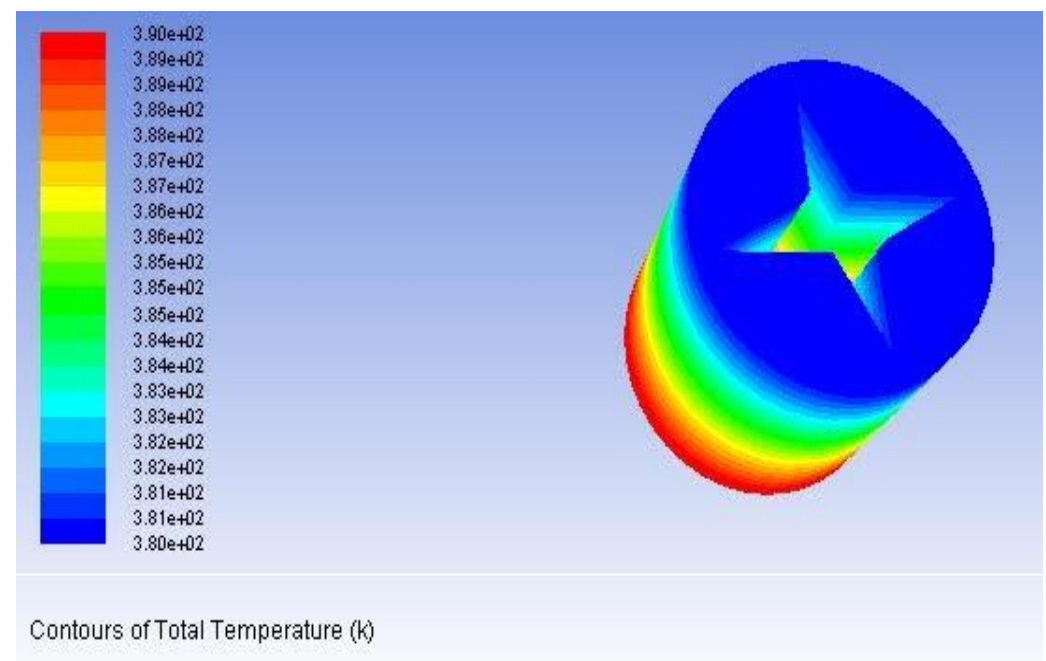

Fig. 4(i) Star Pass

\section{Selection of suitable configuration for TES system}

From various analyses, the charging time for each configuration was estimated. The charging time for various configurations is shown in Figure 5.

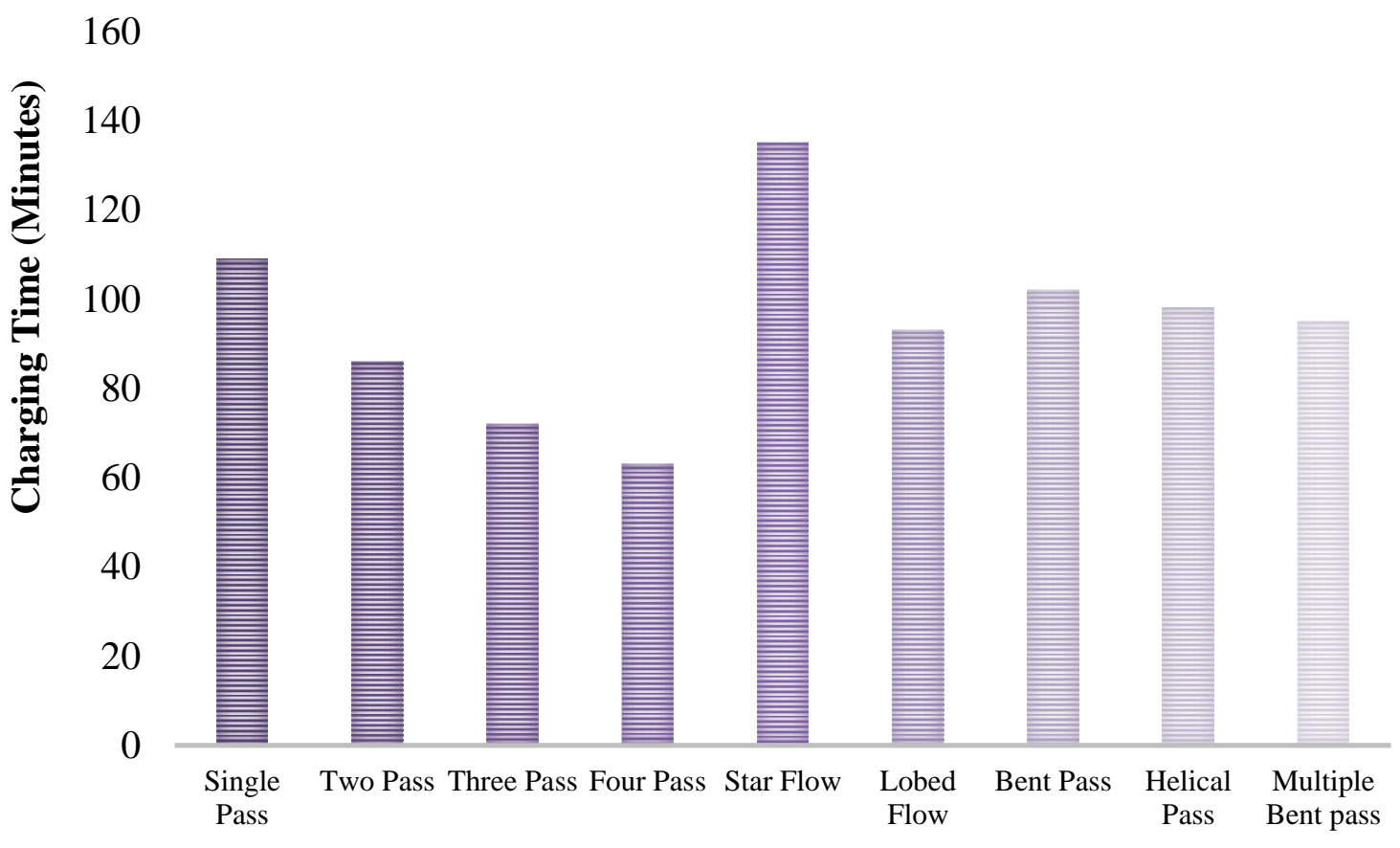

Figure 5. Results for Charging Time for Various Configurations

It can be inferred that the four-pass configuration has the minimum charging time and hence it can be concluded that multipass configurations would suit the case. Also, this configuration has ease of fabrication, and also the pressure drop is also satisfactory 


\section{Experimental evaluation of the prototype}

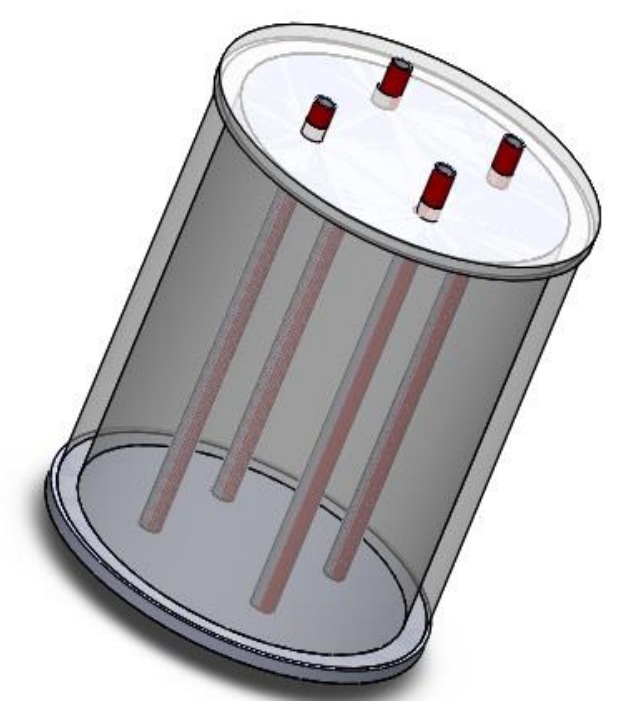

Figure 6. SOLIDWORKS Model of the Prototype

A scaled-down prototype was fabricated to store $1.3 \mathrm{~kJ}$ of heat through $4 \mathrm{~kg}$ of Phase Change Material (Erythritol). The SOLIDWORKS model of the prototype is shown in Fig.6 The Prototype was experimented with to analyze the heat-storing capacity and the charging phenomena. Four pass Configuration was chosen to owe to its betterness in performance in CFD simulations.

It is of necessity that the time taken by the system to completely melt the PCM (charging time) was estimated. The charging time of the PCM must be preferably lower. The charging time of the prototype was experimentally found to be 6 minutes. A CFD transient analysis was also performed to simulate the charging time. The charging time was found to be 4 minutes using CFD Approach. Analytically the charging time was computed to be 2.93 minutes. An energy balance for the prototype was also performed that estimated an energy loss of nearly $3 \%$. The simulation result for the prototype at a fully charged condition is shown in Fig.7.The fabricated prototype is shown in Figure8 and Figure 9.

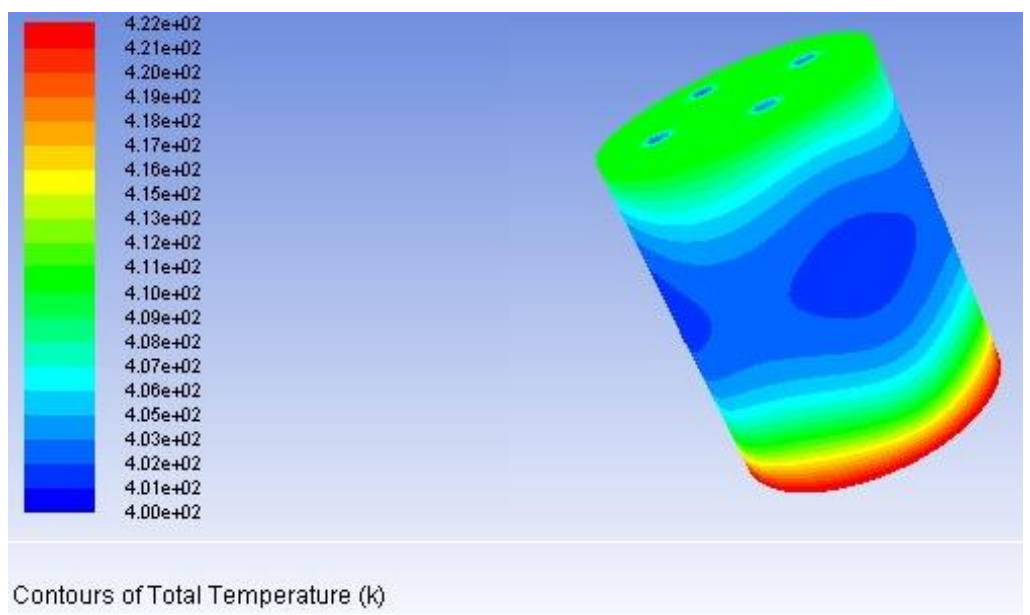

Figure 7. Temperature Contour of Prototype at fully charged state 


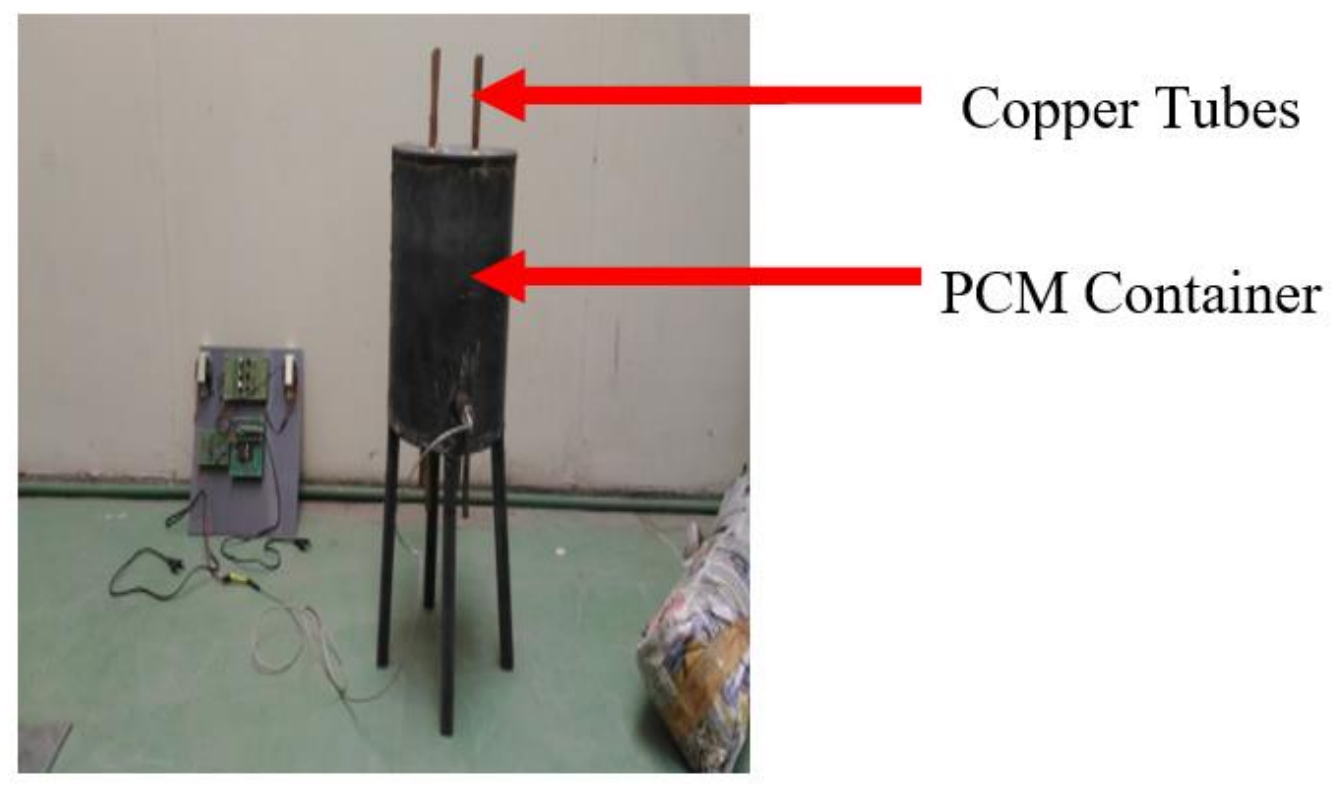

Figure 8. Fabricated Prototype without insulation

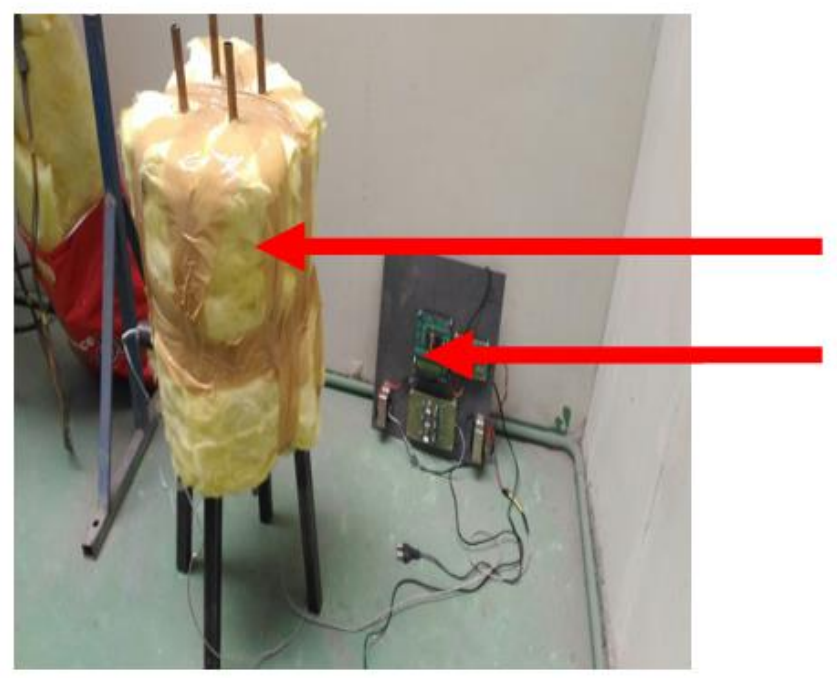

Thermal Wool Insulation Temperature Indicator

Figure 9. Fabricated Prototype with insulation

\section{Conclusion}

This research work focuses on designing and analyzing a thermal energy storage system that would be suitable for steam cooking applications. Various configurations were analyzed and the major findings are as follows:

$\triangleright \quad$ Erythritol has been identified to be the suitable PCM for Steam Cooking applications

$\triangleright$ Various Configurations have been compared and Multiple Tube Configuration is found promising. 
$\triangleright$ The charging time of PCM varies exponentially as the number of tubes increases in Multiple Tube Configuration.

$\triangleright \quad$ The charging time of PCM depends upon the Velocity of HTF, Overall Heat Transfer Coefficient, and Latent Heat of Material.

\section{References}

[1] Guruprasad Alva, Yaxue Lin, Lingkun Liu, Guiyin Fang, Synthesis, characterization and applications of microencapsulated phase change materials in thermal energy storage", Energy and Buildings, 144 (2017) 276-294

[2] M.S. Tayssir, S.M. Eldemerdash, R.Y. Sakr, A.R. Elshamy, O.E Abdellatif, Experimental Investigation of Melting Behavior of PCM by Using Coil Heat Source Inside Cylindrical Container, Journal of Electrical Systems and Information Technology, 2016

[3] Akshay R Hedaoo, Ashwin Hedaoo, Phase Change Material Review, International Journal of Engineering Research and General Science, 4 (2) (2016) 203-208

[4] Lavinia Gabriela Socaciu, Thermal Energy Storage with Phase Change Material, Leonardo Electronic Journal of Practices and Technologies, 20 (2012) 75-98.

[5] R.M Amarasekhara, Energy for Cooking, Integrated Development Association Publication, 1994

[6] Jose Pereira da Cunha, Philip Eames, Thermal Energy Storage for Low and Medium Temperature Application - A Review, Applied Energy, 177(2016) 227-238

[7] Kavendra A. Thakare, A. G. Bhave, Review on Latent Heat Storage and Problems Associated with Phase Change Materials, International Journal of Research in Engineering and Technology, 04(10) (2015) 176-182.

[8] Yi Wang, Yu Zhang, Weihua Yang, Hui Jia, Selection of Low-Temperature PhaseChange Materials for Thermal Energy Storage Based on AHP and VIKOR Method, Energy Storage Science and Technology, 4(3) (2015) 300-305

\section{Acknowledgement}

The authors would like to acknowledge the Department of Science and Technology (DST), Government of India, and PSG College of Technology, Coimbatore for providing financial and technical support towards the accomplishment of the project.

\section{Funding}

This study was not funded by any grant

\section{Conflict of interest}

None of the authors have any conflicts of interest to declare. 


\section{About The License}

The text of this article is licensed under a Creative Commons Attribution 4.0 International License

\section{Cite this Article}

Paul Gregory F, R. Velavan, K. Kannan, Investigations on Phase Change Materials for Thermal Energy Storage (TES) System for Low-Temperature Steam Applications, International Research Journal of Multidisciplinary Technovation, Vol 2, Iss 6 (2020) 1-8.

DOI: https://doi.org/10.34256/irimt2062 